\title{
The short P-wave - Is it really short?
}

\author{
Jakub Mercik ${ }^{1}$, Aleksandra Gajek², Jadwiga Radziejewska ${ }^{2}$, \\ Agnieszka Sławuta ${ }^{3}$, Jacek Gajek ${ }^{4}$, Dariusz Kozłowski ${ }^{5}$ \\ ${ }^{1}$ Department of Emergency Medicine, Wroclaw Medical University, Wroclaw, Poland \\ ${ }^{2}$ Department of Cardiology, Klodzko County Hospital, Klodzko, Poland \\ ${ }^{3}$ Department of Internal and Occupational Diseases, Hypertension and Clinical Oncology, \\ Wroclaw Medical University, Wroclaw, Poland \\ ${ }^{4}$ Department of Emergency Medical Service, Wroclaw Medical University, Wroclaw, Poland \\ ${ }^{5}$ Department of Cardiology and Electrotherapy, Medical University of Gdansk, Poland
}

An 82 year-old woman with atrial flutter and fibrillation (AF), currently in persistent $\mathrm{AF}$, has undergone radiofrequency-ablation of cavotricuspid isthmus and electrical cardioversion to restore sinus rhythm. Electrocardiogram (ECG) after the procedure showed an unusual morphology of the P-wave, which was examined more closely. The ECGs are presented in the Figure 1.

The complete Bachmann's bundle block cannot be recognized because no negative $\mathrm{P}$-wave deflection in inferior ECG leads is present, thus we assume a fusion of concomitant activation of the left atrium through the simultaneously activated Bachmann's bundle and coronary sinus. A more speculative explanation is that the depletion of left atrial cardiomyocytes is leading to a low amplitude of the terminal $\mathrm{P}$ wave deflection [1].

A recent population study of 285,933 individuals assessed the $\mathrm{P}$-wave duration and its clinical importance. In the follow-up the authors observed the development of $\mathrm{AF}$ and cases of death were clearly related to a very short P-wave $(<89 \mathrm{~ms})$. The intermediate, long and a very long P-wave also increased the risk of $\mathrm{AF}$ and death in comparison to reference duration (90-110 ms) [2].

The standard ECG recording could contribute to such measurement inaccuracies which would be responsible for the category of 'short P-wave' and to the conclusions which are having a clinical impact on many patients. In fact, there are interatrial conduction disturbances and prolonged $\mathrm{P}$-wave duration. It should be suspected, especially in the elderly with a history of atrial arrhythmia. To address the issue, we suggest a paper speed of $50 \mathrm{~mm} / \mathrm{s}$ and a double gain of $0.5 \mathrm{mV} / 10 \mathrm{~mm}$.

Conflict of interest: None declared

\section{References}

1. Baranchuk A, Bayés de Luna A. The P-wave morphology: what does it tell us? Herzschrittmacherther Elektrophysiol. 2015; 26(3): 192-199, doi: 10.1007/s00399-015-0385-3, indexed in Pubmed: 26264481 .

2. Nielsen JB, Kühl JT, Pietersen A, et al. P-wave duration and the risk of atrial fibrillation: Results from the Copenhagen ECG Study. Heart Rhythm. 2015; 12(9): 1887-1895, doi: 10.1016/j. hrthm.2015.04.026, indexed in Pubmed: 25916567.

Address for correspondence: Jakub Mercik, MD, Department of Emergency Medicine, Wroclaw Medical University, ul. Borowska 213, 50-556 Wroclaw, Poland, tel: 793166288, e-mail: jakub.mercik@wp.pl

Received: 23.07.2021 Accepted: 21.10.2021

This article is available in open access under Creative Common Attribution-Non-Commercial-No Derivatives 4.0 International (CC BY-NC-ND 4.0) license, allowing to download articles and share them with others as long as they credit the authors and the publisher, but without permission to change them in any way or use them commercially. 


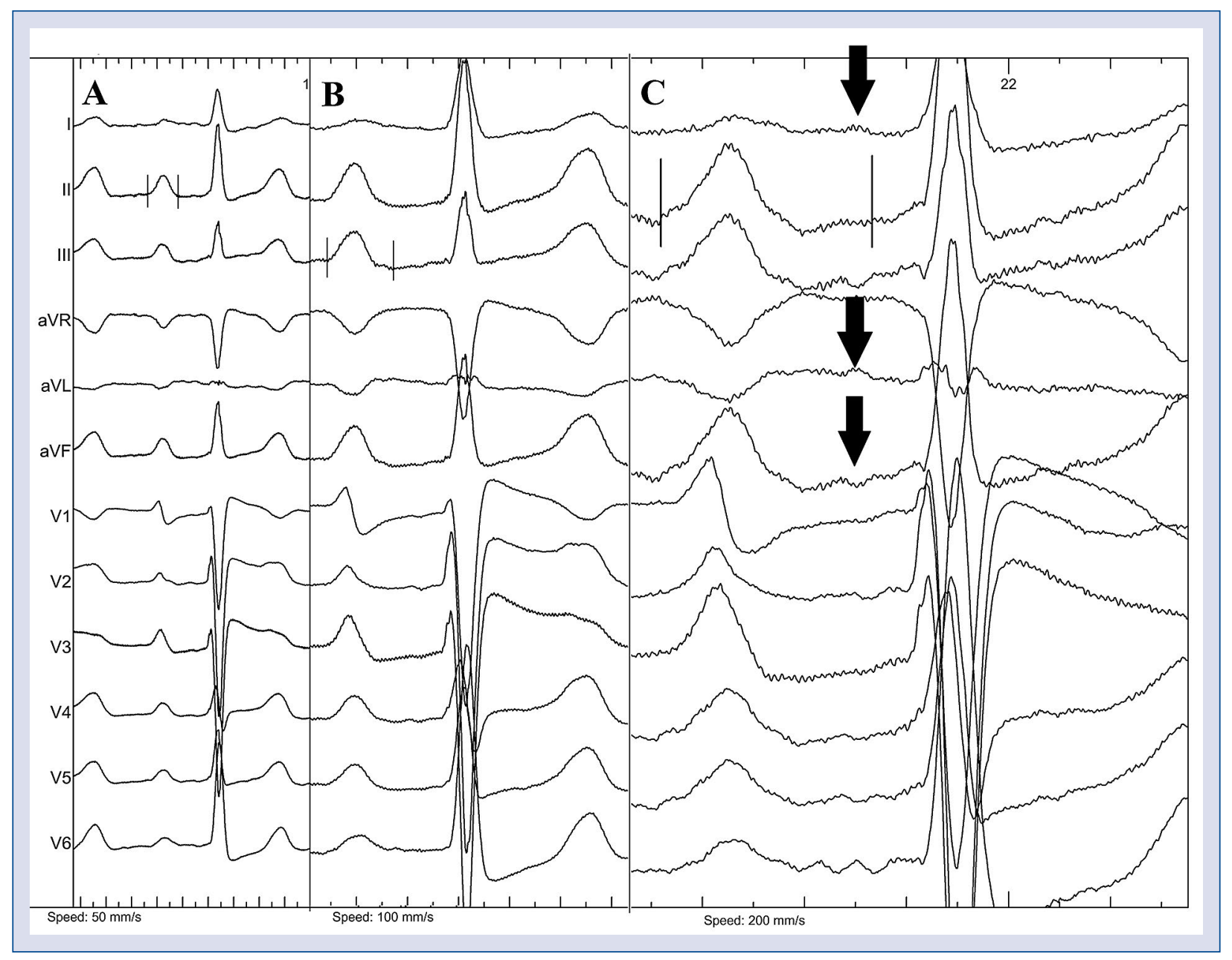

Figure 1. Twelve-lead electrocardiogram tracings; A. Paper speed at $50 \mathrm{~mm} / \mathrm{s}$ and enhancement $\times 16$, the $P$-wave duration of $112 \mathrm{~ms}$, PR interval $216 \mathrm{~ms}$, QRS complex duration $104 \mathrm{~ms}$; B. Paper speed at $100 \mathrm{~mm} / \mathrm{s}$ and enhancement $\times 32$, the P wave duration of $120 \mathrm{~ms}$, PR interval $228 \mathrm{~ms}$, QRS complex duration $102 \mathrm{~ms}$; C. Paper speed at $200 \mathrm{~mm} / \mathrm{s}$ and enhancement $\times 64$, the P-wave duration of $206 \mathrm{~ms}$, PR interval $229 \mathrm{~ms}$, QRS complex duration 99 ms. The vertical lines mark the beginning and the end of the $P$ wave in each setting. The arrow presents the real end of the $P$ wave. 